\title{
Mid-Term Results after Operative Treatment of RockWoOd Grade III-V ACROMIOClavicular Joint Dislocations with AN AC-HoOK-Plate
}

\author{
B. Kienast ${ }^{1}$, R. Thietje ${ }^{1}$, C. Queitsch ${ }^{1}$, J. Gille ${ }^{2}$, A. P. Schulz ${ }^{2}$, J. Meiners ${ }^{1}$ \\ ${ }^{1}$ Department of Traumatology, Orthopaedics and Sports Medicine, BG Trauma Centre Hamburg, Germany \\ ${ }^{2}$ Department of Traumatology, Orthopaedic \& Reconstructive Surgery, University of Schleswig-Holstein, Campus Luebeck, Germany
}

\begin{abstract}
Acromioclavicular joint dislocations often occur in athletic, young patients after blunt force to the shoulder. Several static and dynamic operative procedures with or without primary ligament replacement have been described. Between February 2003 and March 2009 we treated 313 patients suffering from Rockwood III-V lesions of the AC joint with an AC-hook plate. $225(72 \%)$ of these patients could be followed up. Mean operation time was 42 minutes in the conventional group and 47 minutes in the minimal invasive group. The postoperative pain on a scale from 1 to 10 (VAS-scale) was rated 2.7 in the conventional group and 2.2 in the minimal invasive group. Taft score showed very good and good results in 189 patients $(84 \%)$. Constant score showed an average of 92.4 of 100 possible points with $89 \%$ excellent and good results and $11 \%$ satisfying results. All patients had some degree of pain or discomfort with the hookplate in place. These symptoms were relieved after removal of the plate. The overall complication rate was $10.6 \%$. There were 6 superficial soft tissue infections, 1 fracture of the acromion, 7 redislocations after removal of the hook-plate. We observed 4 broken hooks which could be removed at the time of plate removal, 4 seromas and 2 cases of lateral clavicle bone infection, which required early removal of the plate. We can conclude that clavicle hook plate is a convenient device for the surgical treatment of Rockwood Grade III-V dislocations, giving good mid-term results with a low overall complication rate compared to the literature. Early functional therapy is possible and can avoid limitations in postoperative shoulder function.
\end{abstract}

Key words: Acromioclavicular luxation, AC-hook plate, mid-term results, Rockwood III-V

\section{INTRODUCTION}

Acromioclavicular joint dislocations and fractures of the lateral end of the clavicle are common injuries in orthopaedic surgery and sports medicine. These injuries often occur in athletic, young patients after blunt force to the shoulder [1]. While conservative treatment is the option of choice for Rockwood Type I and II acromioclavicular injuries and most fractures of the shaft and the medial part of the clavicle, operative treatment is still discussed controversially for Rockwood type III injuries and is the option of choice for type IV - VI injuries and Jaeger and Breitner type IIa fractures of the lateral clavicle [1-5]. Reason for the instability that lead to a relative dislocation of the lateral clavicle is the involvement of the coracoclavicular ligaments. The mechanism of injury is usually a direct trauma to the superior aspect of the acromion in relation to the distal end of the clavicle $[6,7]$. For the reconstruction of acromioclavicular joint separation several static and dynamic operative procedures with or without primary ligament replacement have been described. Techniques, that focus on the primary healing of the coracoclavicular ligaments, by holding the clavicle in a reduced position, which is usually sufficient in cases of primary reconstruction, include tension bands and K-wires applied through the acromioclavicular joint and extraarticular Bosworth screws to maintain reduction [8]. Both techniques lead to a non-dynamic fixation, which can lead to loosening or breakage of the metalwork $[1,9,10]$. Other more dynamic fixation techniques use plate fixation to keep reduction of the lateral clavicle $[11,12]$. One disadvantage of the Balser plate is that it can only maintain coracoclavicular distance, but not anterior-posterior dislocation and width of the acromiclavicular joint. Early limited physiotherapy is possible after this procedure [13]. Wolter introduced an AC-hook plate with an additional vertical hook as an alternative to the Balser plate in 1882 [14]. This plate complementary maintains reduction of anterior-posterior dislocation and acromioclavicular joint width and can be used for the treatment of acromioclavicular luxation and fractures of the lateral clavicle [15]. In some cases this device also has been used for sternoclavicular joint dislocations [16]. After modification of the plate in 2005 it is also available with locked screws, which gives extra stability for the treatment of fractures of the lateral clavicle and makes minimal invasive application of the plate with the use of only two screws possible. Previous studies proved, that acromioclavicluar fixation techniques are more successful than coracoclavicular fixation techniques [17]. Lately, arthroscopically-assisted repair techniques with focus 
on restoration of the coracoclavicular ligaments have been described and successfully applied for acromioclavicular joint reconstruction using Tight-rope devices $[1,18]$. Today more than 150 different surgical and conservative treatment options are described for the treatment of AC-joint dislocations and they are still discussed controversially [19]. Complication rates vary depending on the different operative technique but can be as high as $60 \%[4,20]$.

\section{Materials AND Methods}

Between February 2003 and March 2009 we treated a consecutive series of 402 patients suffering from complete acromioclavicular separations (Tossy III / Rockwood III-V [21]) and fractures of the lateral end of the clavicle (Jaeger and Breitner type IIa) with the tifix ${ }^{\circledR}$-AC-hook plate (litos/, Hamburg, Germany). Setting was a retrospective multicenter study including the BG Trauma Centre in Hamburg (314 cases) and the University of Luebeck Medical Centre (88 cases). Both Hospitals are Level 1 Trauma Centres. We used the AC-hook plate for the treatment of lesions of the AC joint in 313 cases and for fractures of the lateral clavicle in 89 cases. In this study only the 313 cases with lesions of the AC joint were included, fractures of the lateral clavicle were excluded. Operations were performed in beach-chair position after a median delay of 6 days after trauma (range, $0-42$ days). The surgical technique was performed according to Wolter et al [14]. We performed an approach along the distal clavicle and acromion. After exact reposition of the ACjoint a $5 \mathrm{~mm}$ hole was drilled through the previously bended drill-template. The pre-bended hook of the hook-plate was inserted through the hole and the plate was placed and fixed on the lateral clavicle with three cortical screws for the conventional plate design (Fig. 1). After modification of the plate with locked screws in April 2005 we used minimal invasive surgical technique and a plate with only two screws.

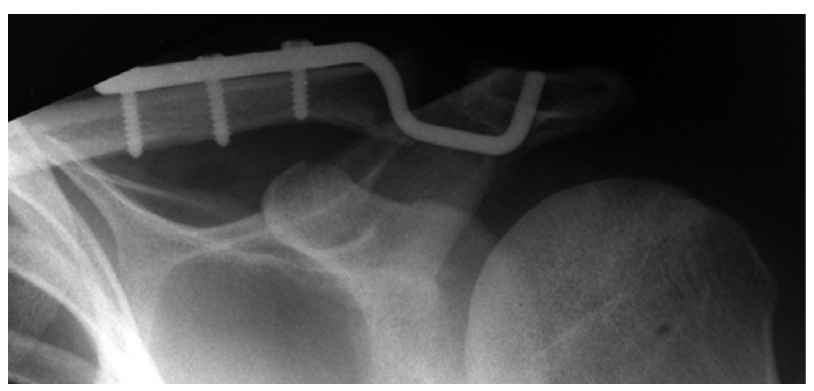

Fig. 1. Implanted AC-hook plate.

The fixation of the screws is based on the principles of angular stable fixation, the screw-heads lock in the plate. The screws are standard angular stable screws. The locking mechanism is gained by a construction developed by Wolter [22]. There is a hole at the end of the vertical hook (Fig. 2). A guide thread can be placed through this. The thread makes it possible to draw the hook into the acromial hole. We always repaired the acromiclavicular ligaments using a Vicryl- suture. The coracoclavicular ligaments were only revised in cases of late reconstruction older than six weeks after trauma or in revision cases.

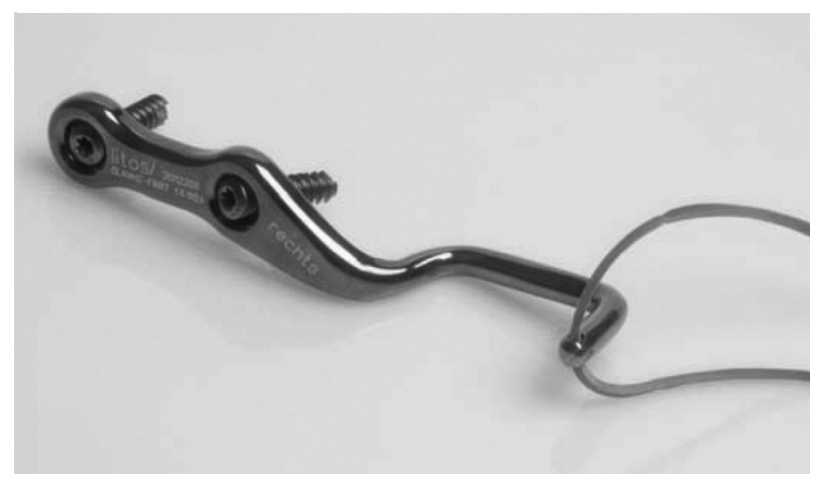

Fig. 2. tifix ${ }^{\circledR}-A C-h o o k$ plate with hole at the end of the vertical hook.

The treatment protocol included inpatient surgery, single shot antibiotics with the use of Cefazolin (Fresenius KaBi Dtl, Bad Homburg, Germany), postoperative immobilisation with Gilchrist-Bandage for four to six days and limitation of ROM to $90^{\circ}$ of abduction and anteversion for six weeks under the instruction of a physiotherapist. Removal of metalwork was scheduled after 12 weeks. After that we treated with physiotherapy for 4 weeks. Minimal invasive approach was used in 134 cases. We included 262 male and 51 female patients. Mean age was 38.4 years (range, 23 68 years). Coherent data of ordinal scaled variables were tested using the Student's t-test. Statistical significance was tested with the Wilcoxon test for related and nonrelated samples. Differences were considered significant at $\mathrm{p}>0.05$.

\section{RESULTS}

225 patients $(72 \%)$ could be followed up within a mean follow-up-period of 36 months (range, 10 - 71 months). At follow up we performed clinical examination with determination of the Constant-Murley and Taft score $[23,24]$. Native $\mathrm{X}$-ray was used to determine AC-joint width (ACJoint) and coracoclavicular distance (CCDistance) in correlation to the preoperative data. We also determined postoperative pain (VAS-scale) and limitation of range of motion (ROM) at follow-up. Mean procedure time was 42 minutes (range, 26 - 56 minutes) in the conventional group and 47 minutes (range, 23 - 77 minutes) in the minimal invasive group without statistical significance (p $>0.05)$. The postoperative pain on a scale from 1 to 10 (VAS-scale) was rated 2.7 (range, 1 - 5) in the conventional group and 2.2 (range, 1 - 4) in the minimal invasive group without statistical significance ( $\mathrm{p}>$ 0.05). Incision length was $34 \mathrm{~mm}$ (range, $31-53 \mathrm{~mm}$ ) in the minimal invasive group (Fig. 2) and $62 \mathrm{~mm}$ (range, $50-72 \mathrm{~mm}$ ) for the conventional group. These differences were significant $(\mathrm{p}<0.05)$.

Concerning the benefit of the procedure we could reduce acromioclavicular joint width from 7.2 millimetres $(\mathrm{mm})$ preoperatively to $3.8 \mathrm{~mm}$ postoperatively. 

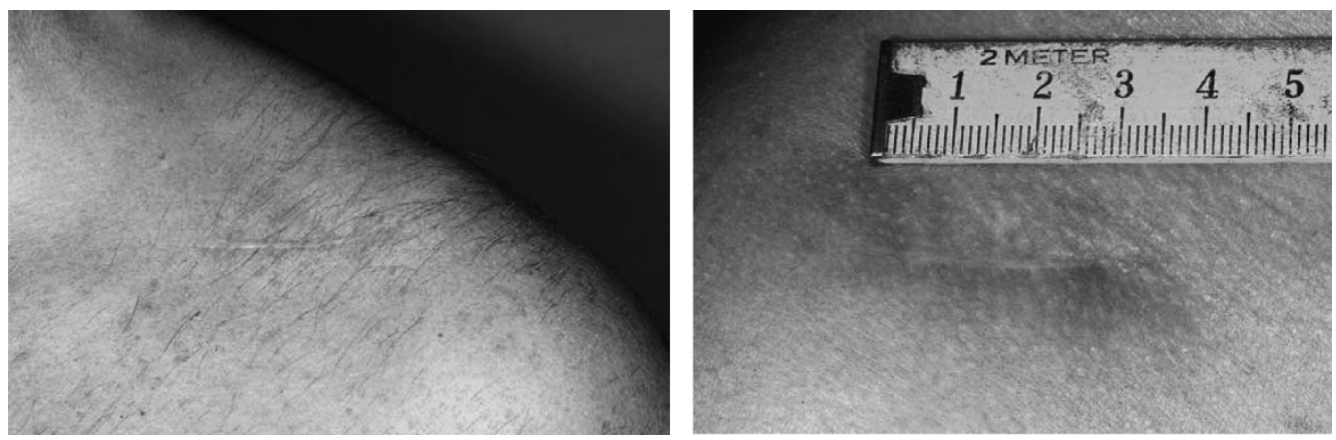

Fig. 3. Minimal invasive approach.

coracoclavicular distance was reduced from $14.6 \mathrm{~mm}$ preoperatively to $11.2 \mathrm{~mm}$ postoperatively (Table.1). We found signs of posttraumatic arthritis in the follow-up radiographs of 32 patients $(14 \%)$ - these patients showed a mean postoperative ACJoint width of $3.1 \mathrm{~mm}$.

Table 1. Results X-Ray.

\begin{tabular}{llcc}
\hline & & Distance in $\mathbf{m m}$ & Range in $\mathbf{~ m m}$ \\
\hline Pre-OP & ACJoint & 7.2 & $5.6-10.3$ \\
& CCDistance & 14.6 & $12.3-18.6$ \\
Post-OP & ACJoint & 3.2 & $2.2-4.3$ \\
& CCDistance & 11.2 & $10.1-13.2$ \\
„Benefit““ & ACJoint & 4.0 & \\
& CCDistance & 3.4 & \\
\hline
\end{tabular}

The Taft score was described by Taft et al in 1987 . It was developed for the evaluation and comparison of AC-Joint function and outcome. The Taft score contains subjective, objective and radiographic criteria. It showed very good and good results in 189 patients $(84 \%)$ (Table 2). The patients acquired an average of 10.6 points (maximum 12 points) in the Taft score. The Constant score [25] for the evaluation of shoulder function showed an average of 92.4 of 100 possible

Table 2. Results Taft Score.

\begin{tabular}{lc}
\hline Taft score & Patients \\
\hline very good & $36(16 \%)$ \\
good & $153(68 \%)$ \\
satisfying & $35(15.6 \%)$ \\
poor & $1(0.4 \%)$ \\
\hline
\end{tabular}

Table 3. Results Constant and Murley Score.

\begin{tabular}{lc}
\hline Constant and Murley Score & Patients \\
\hline excellent & $85(38 \%)$ \\
good & $115(51 \%)$ \\
satisfying & $25(11 \%)$ \\
poor & $0(0 \%)$ \\
\hline
\end{tabular}

points with $89 \%$ excellent and good results and $11 \%$ satisfying results (Table 3). All patients had some degree of pain or discomfort with the hook-plate in place. These symptoms were relieved after removal of the plate.

\section{COMPLiCATIONS}

The overall complication rate was $10.6 \%$ (24 complications). There were 6 superficial soft tissue infections, 1 fracture of the acromion, which was treated with plate osteosynthesis (Fig. 3) and 7 redislocations after removal of the hook-plate. Four of the seven cases with redislocation after plate removal required reoperation with a Weaver-Dunn procedure with good results; the other three patients were satisfied with the results and pain-free despite a moderate remaining AC-joint dislocation. We observed 4 broken hooks which could be removed at the time of plate-removal (Fig. 4), 4 seromas and 2 cases of lateral clavicle bone infection, which needed early removal of the plate. (Table 4).

Table 4. Complications.

\section{Complications}

$\begin{array}{ll}\text { Superficial Soft tissue infection } & 6 \\ \text { Fracture of the Acromion } & 1 \\ \text { Redislocation after hook-plate removal } & 7 \\ \text { Broken hook } & 4 \\ \text { Seroma } & 4 \\ \text { Lateral clavicle Osteitis } & 2\end{array}$

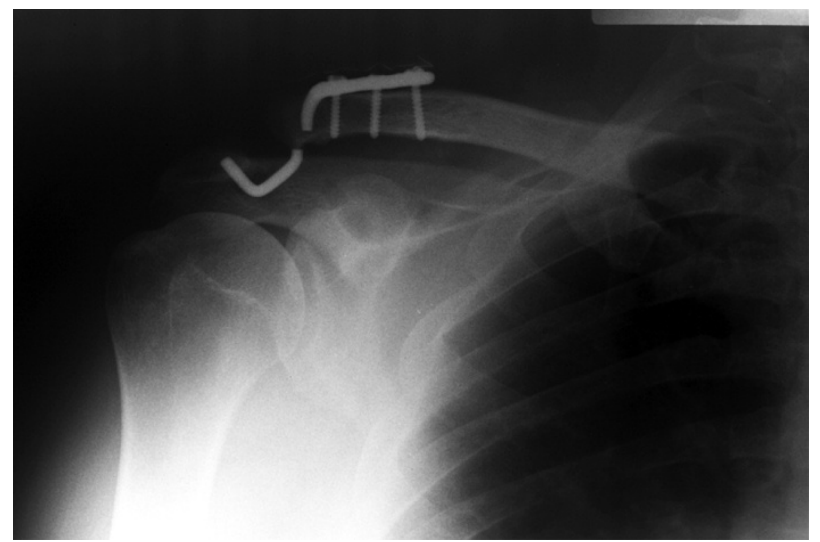

Fig. 4. Broken hook. 


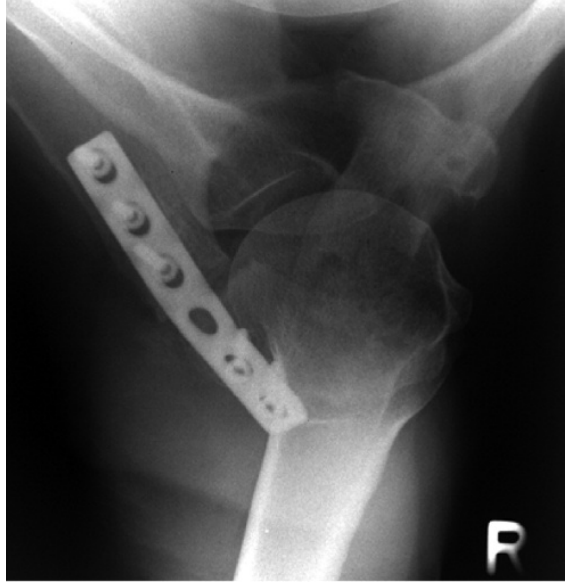

Fig. 5. Fracture of the acromion after plate osteosynthesis.

\section{DISCUSSION}

The AC joint is involved in $4-8 \%$ of joint injuries [26]. In most of the cases sports injuries, especially hiking and road traffic injuries are the reason for AC joint dislocations. Many different types of operative procedures have been described to treat acromioclavicular dislocations and operative versus conservative treatment of Rockwood III lesions is still discussed controversially [2-6]. Results and complication rates of the countless procedures vary [27]. There are other minimal invasive methods available using tight rope devices, without the need for a second operation to remove metalwork, but long term results for these techniques are not yet available [18]. Our satisfying midterm results with a large number of treated patients (313 patients - 225 of these included in this study could been followed up) can be compared to the literature [27-30]. The procedure permits exact positioning and rather rigid retention of the reduction in the transverse and axial plane. The operation can be performed in a minimal invasive technique and with an operation time of less than 50 minutes the procedure is fast and relatively simple. Using the minimal invasive technique with only two fixed-angle screws the procedure time was not extended significantly ( $5 \mathrm{~min}$.), but the length of the scar could be significantly reduced $(28 \mathrm{~mm})$. Taft and Constant-Score of our group showed good results at follow-up concerning ACjoint- and shoulder function.

We can conclude that the tifix ${ }^{\circledR}$-AC-hook plate is a safe device for the surgical treatment of Rockwood Grade III-V dislocations, giving good mid-term results with a low overall complication rate compared to the literature [4]. Early functional therapy is possible and can avoid limitations in postoperative shoulder function [29]. Disadvantage is a second surgical intervention for implant removal and the involvement of the dorsal subacromial space. The modified plate design with locked screws allowed minimal invasive implantation technique and fixation with only two screws. Recent literature proved a high variation in acromial shape, what makes exact positioning of the bended hook essential to prevent irritation of subacromial structures [31]. Further investigation is required to dis- cuss operative versus conservative treatment of Rockwood III lesions. It is controversial if anatomic reconstruction and good radiologic result is essential for a good functional outcome, or not $[32,33]$. Limitation of this study is a missing control group.

\section{REFERENCES}

1. Walz, L., et al., The anatomic reconstruction of acromioclavicular joint dislocations using 2 TightRope devices: a biomechanical study. Am J Sports Med, 2008. 36(12): p. 2398-406.

2. Nuber, G.W. and M.K. Bowen, Acromioclavicular Joint Injuries and Distal Clavicle Fractures. J Am Acad Orthop Surg, 1997. 5(1): p. 11-18.

3. Gstettner, C., et al., Rockwood type III acromioclavicular dislocation: surgical versus conservative treatment. J Shoulder Elbow Surg, 2008. 17(2): p. 220-5.

4. Broos, P., et al., [Surgical management of complete Tossy III acromioclavicular joint dislocation with the Bosworth screw or the Wolter plate. A critical evaluation]. Unfallchirurgie, 1997. 23(4): p. 153-9; discussion 160.

5. Larsen, E., A. Bjerg-Nielsen, and P. Christensen, Conservative or surgical treatment of acromioclavicular dislocation. A prospective, controlled, randomized study. J Bone Joint Surg Am, 1986. 68(4): p. 552-5.

6. Galpin, R.D., R.J. Hawkins, and R.W. Grainger, A comparative analysis of operative versus nonoperative treatment of grade III acromioclavicular separations. Clin Orthop Relat Res, 1985(193): p. 150-5.

7. Luis, G.E., et al., Acromioclavicular joint dislocation: a comparative biomechanical study of the palmaris-longus tendon graft reconstruction with other augmentative methods in cadaveric models. J Orthop Surg Res, 2007. 2: p. 22.

8. Kuchenreuter, G., [Experiences in the nailing of dislocations of the acromioclavicular joint according to Bosworth.]. Chirurg, 1956. 27(6): p. 250-2.

9. Schindler, A., J.P. Schmid, and C. Heyse, [Temporary fixation with the Balser hook plate in the treatment of a fresh and complete acromioclavicular joint dislocation. Results of the follow-up of 41 patients]. Unfallchirurg, 1985. 88(12): p. 533-40.

10. Graupe, F., U. Dauer, and M. Eyssel, [Late results of surgical treatment of Tossy III acromioclavicular joint separation with the Balser plate]. Unfallchirurg, 1995. 98(8): p. 422-6.

11. Albrecht, J., B. Wroblewska, and M.J. Mossakowski, The binding of insulin to cerebral capillaries and astrocytes of the rat. Neurochem Res, 1982. 7(4): p. 489-94.

12. Faraj, A.A. and B. Ketzer, The use of a hook-plate in the management of acromioclavicular injuries. Report of ten cases. Acta Orthop Belg, 2001. 67(5): p. 448-51.

13. Schmittinger, K. and A. Sikorski, [Experiences with the Balser plate in dislocations of the acromioclavicular joint and lateral fractures of the clavicle]. Aktuelle Traumatol, 1983. 13(5): p. 190-3.

14. Wolter, D., C. Eggers, and W. Koch, Die operative Behandlung der akromioklavikulären Luxation und der distalen Klavikulafraktur oder - pseudarthrose mit der ACHakenplatte". Operat. Orthop. Traumatol., 1989. 1(3): p. 145-152.

15. Queitsch, C., et al., Osteosynthesis of Lateral Clavicle Fractures with Hook Plate. Akt Traumatol, 2005. 35: p. 203-207.

16. Gille, J., et al., Hook plate for medial clavicle fracture. Indian J Orthop. 44(2): p. 221-3.

17. Lancaster, S., M. Horowitz, and J. Alonso, Complete acromioclavicular separations. A comparison of operative methods. Clin Orthop Relat Res, 1987(216): p. 80-8. 
18. Salzmann, G.M., et al., Arthroscopic anatomical reconstruction of the acromioclavicular joint. Acta Orthop Belg, 2008. 74(3): p. 397-400.

19. Prokop, A., et al., [Tossy III injuries of the acromioclavicular joint. In what circumstances is surgery still justified? Personal results and literature review]. Orthopade, 2003. 32(5): p. 432-6.

20. Blatter, G. and G. Meier, [Augmentation of the coracoclavicular ligament suture. Comparison between wire cerclage, vicryl tape and PDS cord]. Unfallchirurg, 1990. 93(12): p. 578-83.

21. Tossy, J.D., N.C. Mead, and H.M. Sigmond, Acromioclavicular separations: useful and practical classification for treatment. Clin Orthop Relat Res, 1963. 28: p. 111-9.

22. Wolter, D., U. Schümann, and K. Seide, Universal Titanium Internal Fixator. Trauma Berufskrankh, 1999. 1: p. 12.

23. Taft, T.N., F.C. Wilson, and J.W. Oglesby, Dislocation of the acromioclavicular joint. An end-result study. J Bone Joint Surg Am, 1987. 69(7): p. 1045-51.

24. Haaker, R., et al., [Comparative study of surgically treated shoulder injuries with or without metal implants]. Z Orthop Ihre Grenzgeb, 1994. 132(4): p. 306-11.

25. Constant, C.R. and A.H. Murley, A clinical method of functional assessment of the shoulder. Clin Orthop Relat Res, 1987(214): p. 160-4.

26. Rehn, J. and E. Thelen, [Injuries of the acromioclavicular joint]. Hefte Unfallheilkd, 1975(126): p. 131-6.

27. Ejam, S., T. Lind, and B. Falkenberg, Surgical treatment of acute and chronic acromioclavicular dislocation Tossy type III and V using the Hook plate. Acta Orthop Belg, 2008. 74(4): p. 441-5.

28. De Baets, T., et al., The treatment of acromioclavicular joint dislocation Tossy grade III with a clavicle hook plate. Acta Orthop Belg, 2004. 70(6): p. 515-9.
29. Habernek, H., L. Schmid, and G. Walch, [Management of acromioclavicular joint dislocation with the Wolter hookplate. One year follow-up of 35 cases]. Unfallchirurgie, 1993. 19(1): p. 33-9.

30. Sim, E., et al., Repair of complete acromioclavicular separations using the acromioclavicular-hook plate. Clin Orthop Relat Res, 1995(314): p. 134-42.

31. ElMaraghy, A.W., et al., Subacromial morphometric assessment of the clavicle hook plate. Injury, 2010. 41(6): p. 613-9.

32. Weitzman, G., Treatment of acute acromioclavicular joint dislocation by a modified Bosworth method. Report on twenty-four cases. J Bone Joint Surg Am, 1967. 49(6): p. 1167-78.

33. Sundaram, N., D.V. Patel, and D.S. Porter, Stabilization of acute acromioclavicular dislocation by a modified Bosworth technique: a long-term follow-up study. Injury, 1992. 23(3): p. 189-93.

Received: July 16, 2010 / Accepted: August 4, 2010

Address for correspondence:

Dr. med. Benjamin Kienast

BG Trauma Hospital Hamburg

Bergedorfer Strasse 10

21033 Hamburg

Germany

Fax: +49-40-7306-3704

Tel.: $\quad+49-40-7306-0$

Email: b.kienast@buk-hamburg.de 